Psicologia \& Sociedade; 16 (1): 151-160; Número Especial 2004

\title{
DIREITOS SEXUAIS E REPRODUTIVOS: ALGUMAS CONSIDERAÇÕES PARA AUXILIAR A PENSAR O LUGAR DA PSICOLOGIA E SUA PRODUÇÃO TEÓRICA SOBRE A ADOLESCÊNCIA
}

\author{
Maria Juracy Filgueiras Toneli \\ Universidade Federal de Santa Catarina
}

RESUMO: O objetivo deste texto é discutir questôes que dizem respeito à saúde sexual e reprodutiva dos adolescentes, considerando-se dois eixos fundamentais: a noção de direitos sexuais e reprodutivos fundamentada no que as grandes conferências promovidas pela ONU na década de 90 do século passado preconizam e o discurso médico-científico como dispositivo que oscila entre as estratégias de governo das populações (governamentalidade) e a incitação do sujeito para se ocupar de si mesmo (tecnologias/governo de si). A noção de biopoder, segundo Foucault, mostra-se promissora nesta discussão que inclui o olhar sobre os dispositivos que constituem o sujeito em sua dupla dimensão: sujeito a alguém ou a algo e atado à sua identidade pela consciência e autoconhecimento.

PALAVRAS-CHAVE: biopoder, governamentalidade, saúde sexual.

SEXUAL AND REPRODUCTIVE RIGHTS: SOME

CONSIDERATIONS TO ASSIST THE THINKING ABOUT

THE ROLE OF PSYCHOLOGY AND ITS THEORETHICAL

PRODUCTION ABOUT ADOLESCENCE

ABSTRACT: The objective of this text is to discuss some issues regarding adolescents' sexual and reproductive health, considering two fundamental axes: the notion of sexual and reproductive rights based on what the great conferences promoted by United Nations on the nineties of last century praised and the medical-scientific speech as device which oscillates between government strategies of the populations ("governmentability") and the subject's incitation to be occupied with himself (technologies/self-goverment). The notion of "biopower", according to Foucault, seems to be promising in this discussion which includes the view on the devices that constitute the subject in his double dimension: subjected to 
Toneli, M. J. F.

"Direitos sexuais e reprodutivos..."

someone or to something and tied to his identity through conscience and self-knowledge.

KEYWORDS: biopower, governmentability, sexual health.

Le libéralisme nest évidemment pas une idéologie ni un idéal. C'est une forme de gouvernement et de 'racionalité' gouvernementale fort complexe. (FOUCAULT, 1999, p. 36)

Em 1990 foi publicada, no Brasil, a lei n.o 8069, denominada "Estatuto da Criança e do Adolescente", que ficou conhecida pela sigla ECA. Embora se possa argumentar com relação à enorme distância existente entre a lei e sua real aplicação, deve-se reconhecer a iniciativa do Estado brasileiro em afirmar, ao menos no papel, que crianças e adolescentes são sujeitos de direitos abstratos e em se estabelecer como guardião destes direitos. De fato, nas duas últimas décadas houve um avanço considerável nas políticas públicas voltadas para a infância e a juventude no Brasil. Entre as iniciativas deste período pode-se apontar a criação do Conselho Nacional da Criança e do Adolescente, o Programa de Atenção Integral à Saúde da Mulher, o Programa de Saúde do Adolescente, o Programa de Prevenção e Controle das Doenças Sexualmente Transmissíveis e do HIV/Aids, a inclusão da educação sexual nos Parâmetros Curriculares Nacionais e da sexualidade como tema transversal na área da educação (RIOS, PIMENTA, BRITO, TERTO JÚNIOR \& PARKER, 2002).

É preciso, no entanto, pensar estas iniciativas, em um cenário que inclui agentes sociais bastante diversificados que disputam a tutela da infância e da juventude no contexto brasileiro. Além do Estado, a Igreja Católica e o campo médico-científico, cada qual com suas concepções a respeito das características e necessidades das populações jovens em seus vários níveis de produção e integração na realidade social, historicamente afirmaram-se como agências importantes nesse jogo de forças que, simultaneamente, engendra processos de subjetivação.

Do ponto de vista histórico, a noção de direitos associa-se à de indivíduo, ambas produtos da modernidade e da doutrina liberal. É nesse contexto que se consolida a divisão entre a esfera pública e a 
privada, remetendo à última os aspectos relativos à intimidade como aqueles da ordem da sexualidade. Consolidou-se, também, a naturalização da associação entre o âmbito privado, a reprodução e as mulheres, enquanto que a produção estaria localizada na esfera pública e realizada pelos homens.

Embora se possa afirmar que mudanças venham acontecendo no cenário acima descrito, incluindo a própria noção de individualidade que é colocada em cheque pelo mundo virtual globalizado, pelas novas tecnologias de comunicação e pelas novas tecnologias reprodutivas, as concepçóes que ordenam a vida segundo tempos e espaços demarcados persistem no imaginário e nas práticas sociais. É assim, por exemplo, que os discursos normativos, prescritivos, higienistas ainda se mantêm subjacentes às açôes voltadas para o controle das populaçōes jovens, especialmente nos campos da saúde e da educação.

É neste contexto que persiste o discurso adultocentrado prescritivo e normalizador que atribui à adolescência um caráter essencialista a-histórico que inclui características como irresponsabilidade, instabilidade, rebeldia, imaturidade, marcando uma etapa do ciclo vital definida em termos de faixa etária através de um viés organicista. A adolescência assim definida parece mais um fenômeno circunscrito às populações de camadas médias e elites urbanas submetidas à influência do discurso médico (RIOS, PIMENTA, BRITO, TERTO JÚNIOR \& PARKER, 2002) e ao individualismo moderno conforme o modelo dumontiano (HEILBORN, 1998). As política públicas, assim como determinadas matrizes conceituais, parecem ainda desconhecer a importância dos elementos de ordem institucional (organizações escolares, familiares, religiosas, entre outras) e social (relações de gênero, classe, raça/etnia, gerações) na constituição dos processos de passagem da infância à maturidade, determinando os lugares dos atores sociais e sua qualidade de vida.

O objetivo deste texto é justamente discutir estas questões no que diz respeito à saúde sexual e reprodutiva dos adolescentes, considerando-se dois eixos fundamentais: 1) a noção de direitos sexuais e reprodutivos fundamentada no que as grandes conferências promovidas pela ONU na década de 90 do século passado 
Toneli, M. J. F.

"Direitos sexuais e reprodutivos..."

preconizam; 2) o discurso médico-científico como dispositivo que oscila entre as estratégias de governo das populaçôes (governamentalidade) e a incitação do sujeito para se ocupar de si mesmo (tecnologias/ governo de si). A noção de biopoder, segundo Foucault, mostra-se promissora nesta discussão que inclui o olhar sobre os dispositivos que constituem o sujeito em sua dupla dimensão: sujeito a alguém ou a algo e atado à sua identidade pela consciência e autoconhecimento. É também em Foucault que se pode encontrar a idéia de governamentalidade entendida como um conjunto de práticas, procedimentos, análises que exercem uma determinada forma de poder sobre a população (FOUCAULT, 1994a e b).

\section{DIREITOS SEXUAIS E REPRODUTIVOS: A CONSTITUIÇÃO DO CONCEITO}

Embora o termo direitos reprodutivos tenha surgido explicitamente com a criação da Rede Mundial pela Defesa dos Direitos Reprodutivos das Mulheres em 1979, desde o início do século XX pode-se identificar uma demanda do movimento de mulheres pelo controle da própria capacidade reprodutiva. Na I Conferência Mundial de Direitos Humanos de 1968, em Teerã, finalmente reconheceu-se o direito da pessoa a decidir sobre sua reprodução.

$\mathrm{Na}$ realidade estas discussōes engendraram o questionamento da maternidade como projeto compulsório das mulheres, mais além de suas conseqüências numéricas ou da época de sua concretização. Ou seja, tratava-se da discussão do desejo ou não de ser mãe e da discriminação social se este desejo fosse o de não o ser, ou seja, de sua imposição às mulheres. A discussão dos direitos reprodutivos no âmbito dos direitos humanos significou um avanço no sentido de que não importava o sexo/gênero da pessoa, sua religião, idade, raça/etnia, grupo social de pertença e, sim, que qualquer um deve ser reconhecido como sujeito de direitos neste campo e deveria ter asseguradas as condiçóes para o exercício pleno destes direitos.

No processo de consolidação do conceito de direitos reprodutivos, foram de grande relevância as grandes conferências 
organizadas pela ONU, na década de 90: a Conferência Internacional de População e Desenvolvimento, realizada no Cairo, em 1994 e a IV Conferência Mundial Sobre a Mulher, realizada em Beijing, em 1995. Através delas, as reivindicações dos movimentos das mulheres tiveram o alcance institucional necessário para expandir suas idéias aos campos de intervenção na área da saúde reprodutiva. Destacase, como marco principal, a conferência realizada no Cairo, por ter proposto a superação da perspectiva de saúde reprodutiva que enfatiza o controle da natalidade, além de ter reconhecido a sexualidade enquanto uma esfera positiva da atuação humana (Barzelatto, 1998) que inclui sexo, identidades e papéis de gênero, orientação sexual, erotismo, prazer, intimidade e reprodução (WHO, 2002).

Segundo a definição adotada pela Organização Mundial de Saúde (WHO, 2002), os direitos sexuais seguem os direitos humanos que já são reconhecidos pelas leis e documentos internacionais consensuais. Eles incluem o direito de todas as pessoas e repudiam qualquer forma de coerção, discriminação ou violência, devendo ser protegidos e respeitados.

No Brasil, desde a década de 60, agências internacionais que financiam projetos de investigação e/ou intervenção na área da saúde reprodutiva, tiveram um papel importante no sentido de agregar pessoas e idéias, a partir da noção ampliada de saúde enquanto direito básico que inclui a sexualidade e a reprodução. Pode-se constatar, no entanto, uma tendência por parte de campos discursivos distintos - em especial, o governamental, o religioso e o médico-científico - a fomentar políticas de caráter controlista que aviltavam esta noção de direitos, submetendo a população a práticas que visavam a redução da natalidade a qualquer custo. Tratava-se claramente aqui de estratégias biopolíticas destinadas a dirigir e controlar as condutas sexuais e reprodutivas com fins de controle demográfico, em especial nos países de terceiro mundo. Como forma de resistência/ enfrentamento destas políticas, programas de pesquisa foram instituídos no intuito de subsidiar novas práticas de intervenção que fossem ao encontro da construção do exercício da cidadania também no campo da reprodução. No entanto, pode-se identificar um impasse neste cenário na medida em que o sistema liberal que 
Toneli, M. J. F.

"Direitos sexuais e reprodutivos..."

preconiza a liberdade de iniciativa e os direitos individuais vê-se às voltas com "problemas" colocados às práticas de intervenção pelas necessidades governamentais de administração e controle de determinadas situações associadas à vida das populaçôes.

$\mathrm{O}$ interesse particular em estudar a presença dos homens no campo da saúde sexual e reprodutiva tem seu início em torno dos anos 80 do século passado em função de duas constatações fundamentais que se associam à noção de direitos tal como vem sendo desenvolvida aqui: o aumento da incidência da Aids, em especial no segmento constituído por mulheres casadas, e o papel que os homens exercem na regulação das estratégias preventivas e contraceptivas de suas parceiras (VILLA, 1998). Pode-se constatar, no entanto, que a maioria dos estudos sobre os processos reprodutivos ainda exclui os homens deste cenário, considerando a mulher como agente exclusivo da reprodução. Tal situação estaria associada ao pressuposto, vigente nas concepçôes da modernidade sobre gênero e família, de que os homens estariam associados a esferas de interesse ligados ao exercício da sexualidade e à atividade produtiva, enquanto que as mulheres estariam mais circunscritas aos interesses vinculados à reprodução e ao cuidado dos filhos no âmbito privado (LEAL \& BOFF, 1996). Este pressuposto é o que faz com que, por exemplo, as pesquisas censitárias e demográficas continuem limitando à mãe as informaçôes sobre os fatos da vida reprodutiva (LYRA \& MEDRADO, 2000).

As conferências internacionais já mencionadas tematizaram as questôes voltadas para as populações jovens incluindo aquelas relacionadas à saúde e aos direitos sexuais e reprodutivos. Incorporando uma analítica de gênero, buscaram elaborar diretrizes que apontam para a necessidade de garantir a eqüidade neste campo marcado por desigualdades históricas e buscaram denunciar o descompasso entre os direitos adquiridos na esfera pública e seu exercício efetivo na vida cotidiana das pessoas. No entanto, persiste a insuficiência da problematização dos aspectos subjacentes aos comportamentos neste campo, marcadamente associados à moral e aos valores propugnados pelos grupos culturais em suas relaçóes societárias. 


\section{O DISCURSO MÉDICO-CIENTÍFICO SOBRE A SEXUALIDADE COMO DISPOSITIVO DE CONTROLE DAS POPULAÇÕES JOVENS E O CONTEXTO CONTEMPORÂNEO}

O modelo hegemônico de masculinidade na modernidade ocidental preconiza uma vida sexual ativa para os homens através da qual se constrói um de seus indicadores fundamentais: a virilidade. Nesta perspectiva essencialista, há a idéia de um impulso natural do desejo sexual nos homens que, no entanto, deverão controlá-lo ou administrá-lo em função de suas consequiências reprodutivas. Este modelo assume nuances variadas conforme o grupo cultural e, entre outros aspectos, a origem de classe. Nas populações urbanas de camadas médias, uma ideologia igualitarista vem ganhando espaço, defendendo a desconstrução das distinções de gênero como marcadores dos lugares ocupados pelos atores sociais nos diversos âmbitos da vida, incluindo o familiar. Outras formas de distinções, como a geracional, também são colocadas em xeque.

No entanto, em se tratando de sociedades complexas, coexiste com a ideologia individualista/igualitarista, uma configuração holista mais tradicional na qual a família e as relações hierárquicas entre os sexos e as gerações mantêm-se como ordenadoras da vida. Tratam-se apenas de modelos e obviamente os sujeitos concretos não correspondem a eles em sua forma absoluta. Esta metáfora, contudo, parece útil para explicar a complexidade das relaçôes sociais e dos ordenamentos simbólicos contemporâneos.

No caso dos adolescentes, esta complexidade mostra-se ainda mais visível e imperiosa, na medida em que são "filhos" convivendo, em geral, numa rede familiar e dependentes de seus pais de forma a não terem condições de assumir a responsabilidade pela paternidade, uma vez que, incapazes de estar em condiçôes materiais e subjetivas de "formar uma família" (VILLA, 1999). O projeto centrado no trabalho e/ou estudo é imposto ao adolescente, inviabilizando ou negando a possibilidade da paternidade nesta fase do ciclo vital. Espera-se, portanto, que o adolescente "controle" seus impulsos sexuais, embora, espere-se, também, que não os controle, uma vez 
Toneli, M. J. F.

"Direitos sexuais e reprodutivos..."

que é significado socialmente como irresponsável. Ademais, trata-se de um homem e deve mostrar-se viril. A tensão estabelecida entre a concretização destes impulsos - traço visto como masculino - e sua incontrolabilidade, por um lado, e, por outro, a noção moral de responsabilidade parece traçar um quadro no qual o adolescente vêse duplamente sujeitado - pela "natureza" e pela moral. Por outro lado, sua assunção à maturidade significa submeter-se ao ditame "conheça a si mesmo" e assuma as consequiências de suas ações no mundo.

Pode-se afirmar, segundo Foucault, que a partir do século XVIII surge uma série de dispositivos na tentativa de racionalizar os problemas colocados à prática governamental pelos fenômenos próprios a uma população: saúde, higiene, natalidade etc. (FOUCAULT, 1994a, p.125). A biopolítica surge, então, como uma forma de governamentalidade, ou seja, como uma série de técnicas e procedimentos destinados a dirigir a conduta de homens, mulheres, crianças, almas... No entanto, como levar em conta estes fenômenos em um sistema que, ao menos em tese, baseava-se no respeito ao sujeito de direito e à liberdade de iniciativa dos indivíduos: o liberalismo?

Entram em cena aqui o que Foucault chamou de "técnicas de si", ou seja, "procedimentos, pressupostos ou prescritos aos indivíduos para fixar sua identidade, mantê-la ou transformá-la em função de determinados fins, e isso graças a relaçōes de domínio de si sobre si ou de conhecimento de si por si" (FOUCAULT, 1994b, p. 213). Trata-se de "conhecer-se a si mesmo" ou "governar-se", ou seja, o governo de si por si na sua articulação com relação ao outro, como no caso da pedagogia, da prescrição dos modelos de vida (como no campo da saúde), da orientação espiritual, e assim por diante (ibid., p. 214).

No caso dos adolescentes, pode-se acompanhar o cruzamento do bipoder/biopolítica - controle sobre as populações adolescentes através de mecanismos prescritivos e normativos, uma vez que os adolescentes ainda não são capazes de se governarem, e, as tecnologias de si - inquisição do sujeito no sentido da reflexão sobre os modos de vida, de regular a sua conduta de si, de fixar a si mesmo meios e 
Psicologia \& Sociedade; 16 (1): 151-160; Número Especial 2004

fins (ibid., p. 215). O discurso da saúde pública oscila entre estas duas tendências fundamentais, amparado, entre outras áreas pela Psicologia que, em seus trabalhos, ainda mantém a concepção de fase de transição, moratória e crise a respeito da adolescência.

Considerando-se a noção de direitos sexuais e reprodutivos tal como foi apresentada neste texto, pode-se afirmar que, no caso dos adolescentes, trata-se de um paradoxo. Como tal, impossível de ser resolvido, uma vez que o próprio conceito de adolescência engendra a idéia de alguém que ainda não é capaz de cuidar de si de maneira autônoma, racional e livre como supóe o discurso liberal sobre o qual se funda a noção de direitos. Resta, portanto, controlar os adolescentes, na expectativa de um devir que, neste caso, significa o autocontrole através das tecnologias de si. Nesta direção, a Pedagogia e a Psicologia ganham destaque e perpetuam relaçōes de saber-poder que pretendem prevenir e/ou curar aqueles que ousam criar sua existência fundados em outra ética que não seja a do aprisionamento à norma.

\section{REFERÊNCIAS}

BARZELATO, J. (1998). Desde el control de la natalidad hacia la salud sexual y reproductiva: la evolución de un concepto a nivel internacional. Em BILAC, E. D. \& ROCHA, M. I. B. (Orgs.) Saúde reprodutiva na América Latina e no Caribe: temas e problemas, (pp. 39-49). Campinas: PROLAB, ABEP, NEPO, UNICAMP.

FOUCAULT, M. (1994a). Du gouvernement des vivants. In: Dits et écrits (IV), (pp. 125-129). Paris: Gallimard.

FOUCAULT, M. (1994b). Subjectivité et vérité. In: Dits et écrits (IV), (pp. 213-218). Paris: Gallimard.

HEILBORN, M. L. (1998). Gravidez na Adolescência: consideraçōes preliminares sobre as dimensões culturais de um problema social. Em: Vieira, E. M., Fernandes, M. E. L., BAILEY, P. \& MCKAY, A. (Orgs.) Seminário Gravidez na Adolescência, (pp. 23-32). Rio de Janeiro: Associação Saúde da Família. 
Toneli, M. J. F.

"Direitos sexuais e reprodutivos..."

LEAL, O. F. \& BOFF, A. (1996). Insultos, Queixas, Sedução e Sexualidade: Fragmentos de Identidade Masculina em uma perspectiva relacional. Em: Parker, R. \& Barbosa, R. M. (Org.) Sexualidades Brasileiras, (pp. 119-135). Rio de Janeiro: Relume Dumará.

LYRA, J. \& MEDRADO, B. (2000). Gênero e paternidade nas pesquisas demográficas: o viés científico. REF, 8 (1), 145-158.

RIOS, L. F., Pimenta, C., Brito, I., Terto Júnior, V. \& Parker, R. (2002). Rumo à adultez: oportunidades e barreiras para a saúde sexual dos jovens brasileiros. Cadernos CEDES, 22 (57), 45-61.

VILLA, A. M. (1999). Sexualidad, Reproducción y Paternidad: una introduccional analisis de la demanda social en las relaciones de género. Em: Marques Da Silva, D. P. (Org.) Novos contornos no espaço social: gênero, geração e etnia, (pp. 7-22). Rio de Janeiro: UERJ, NAPE.

VILLA, A. M. (1998). Haciendo visible a los varones en las relaciones de género. Sexualidade, gênero e sociedade, 7/8, Rio de Janeiro: CEPESC/IMS/UERJ.

WHO. World Healthy Organization. www.who.int

$$
\begin{array}{r}
\text { Maria Juracy Filgueiras Toneli , é professora da Universidade Federal } \\
\text { de Santa Catarina. O endereço eletrônico da autora é: } \\
\text { juracy@cfh.ufsc.br }
\end{array}
$$

Maria Juracy Filgueiras Toneli.

Direitos sexuais e reprodutivos: algumas consideraçôes para auxiliar a pensar o lugar da Psicologia e sua produção teórica sobre a adolescência

Recebido: 3/11/2003

Aceite final: 8/01/2004 